\title{
New frontiers in VATS lobectomy learning: the experience of the thoracic surgery residency program in Milan
}

\author{
Alessandra Mazzucco, Alessandro Palleschi, Valeria Musso, Gianluca Bonitta, Mario Nosotti \\ Thoracic Surgery and Lung Transplant Unit, Fondazione IRCCS Ca' Granda Ospedale Maggiore Policlinico, University of Milan, Milan, Italy \\ Contributions: (I) Conception and design: A Palleschi, A Mazzucco; (II) Administrative support: A Mazzucco; (III) Provision of study materials or \\ patients: A Mazzucco, V Musso; (IV) Collection and assembly of data: A Mazzucco; (V) Data analysis and interpretation: A Mazzucco, G Bonitta; (VI) \\ Manuscript writing: All authors; (VII) Final approval of manuscript: All authors. \\ Correspondence to: Alessandra Mazzucco, MD. Thoracic Surgery and Lung Transplant Unit, Fondazione Cà Granda Ospedale Maggiore Policlinico, \\ Milan, Italy. Email: alessandra.mazzucco@hotmail.it.
}

Background: Video-assisted thoracoscopic technique (VATS) is being increasingly adopted for the treatment of thoracic diseases, and it is therefore replacing traditional approaches. Young thoracic surgeons are now required to perform VATS anatomical resections, but a solid experience in open surgery is considered essential to face VATS lobectomy. On the other hand, open lobectomy is mostly reserved for complex cases. The aim of this study was to assess the impact of the trainees' practice on the outcome of VATS major pulmonary resections in a teaching hospital setting.

Methods: We retrospectively analysed surgical activity in our University Hospital from January 2011 to August 2019. Inclusion criteria were: lobectomy and anatomical segmentectomy. Exclusion criteria were: bilobectomy, pneumonectomy and anatomical resection with arterial or bronchial plastic and wall resection. We divided the patients in two groups: Group T includes patients operated by a trainee, and Group S includes patients operated by a senior surgeon. We collected all demographical and pre-operative data, surgical, postoperative and histological data. We considered 30 and 90 days mortality and overall survival. Continuous variables are expressed as mean values and standard deviation, categorical variables are expressed with absolute and percentage frequencies. Two-sided Chi-square tests or T-tests for unpaired data were performed as appropriate. A p-value $<0.05$ was considered statistically significant.

Results: A total of 857 procedures were performed over the study period. Excluding bilobectomies, pneumonectomies and anatomical resections with arterial or bronchial sleeve or wall resections, we selected 742 interventions: 688 lobectomies (92.7\%) and 54 anatomic segmentectomies $(7.3 \%)$. Residents carried out 58 operations: 43 anatomical resections (74.1\%) were performed adopting VATS approach (Group T). Senior surgeons performed 684 operations: 452 anatomical resections (58.7\%) in VATS (Group S). There were no statistically significant differences between the two groups in terms of demographic, clinical or pathological factors, operative data, post-operative complications and mortality. Overall survival at 5 years was $74.3 \%$ in Group T and $72.2 \%$ in Group S.

Conclusions: This study shows that trainees, even with partial experience in open lobectomy, can safely perform VATS major pulmonary resections. In our series, trainee practice did not affect surgical time, conversion rate, post-operative outcomes, oncological radicality and mortality. We think that University Hospitals could safely include VATS lobectomy in the training program.

Keywords: Video-assisted thoracoscopic surgery lobectomy (VATS lobectomy); trainees; learning curve

Received: 23 December 2019; Accepted: 10 February 2020; Published: 25 August 2020.

doi: $10.21037 /$ ccts.2020.02.06

View this article at: http://dx.doi.org/10.21037/ccts.2020.02.06 


\section{Introduction}

Video-assisted thoracoscopic technique is being increasingly adopted for the treatment of thoracic diseases, and it is replacing traditional open approaches because of its important advantages in terms of postoperative outcomes (i.e., hospital stay, complications, postoperative pain) (1). Among major pulmonary resections, lobectomy is the most common procedure, and therefore video-assisted thoracoscopic technique (VATS) lobectomy has become the most frequent operation in thoracic surgery. Indeed, several studies provided strong evidence that this minimally invasive approach for lobectomy is safe and guarantees the same oncological radicality as thoracotomy, in patients with lung cancer $(2,3)$.

Some studies focusing on the VATS lobectomy learning curve claim that the number of procedures to achieve is 50 , but the authors only considered surgeons with an extensive experience in open lobectomy (4-7). This scenario has a great impact on residents' surgical training. In fact, the indications for open lobectomy have become progressively rare, and are mostly reserved to complex cases, which are usually performed by skilled; also, it would not be ethically correct to perform easy procedures by thoracotomy for the only purpose of teaching residents. This leaves the trainee with few opportunities to perform open surgery but, on the other hand, it is still a widespread belief that learning the open technique should necessarily be the first step towards learning VATS.

The aim of this study was to assess the impact of the trainees practice on the outcome of VATS major pulmonary resections in a teaching hospital setting.

\section{Methods}

This is a retrospective study using prospectively collected data of consecutive patients who underwent major pulmonary resections from January 2011 to August 2019 at our institution, which is the leading centre of the Milan Thoracic Surgery Residency School. Inclusion criteria were: adult patients ( $\geq 18$ years), informed consent obtained, patients undergoing anatomical lung resection (lobectomies and segmentectomies). We excluded bilobectomies, pneumonectomies, and lobectomies requiring arterial/ bronchial plastic or wall resection.

All VATS procedures were performed by standardized three-port anterior approach (Copenhagen) (8), or by single-port approach as reported by Gonzales-Rivas (9).
Open technique resections were performed using a musclesparing thoracotomy as previously described (10). The lymphadenectomy was carried out according to ESTS Guidelines (11). We consider a systematic lymphadenectomy to be adequate when at least 14 lymph nodes are removed and 4 or more lymph node stations are sampled $(11,12)$. Residents were always tutored by a senior surgeon.

We collected all demographical and pre-operative (age, sex, comorbidities, induction therapy, previous surgery, FEV1 and DLCO), surgical and histological data (type of resection, operative time, hospital stay, conversion rate, postoperative morbidity, histology, pathologic stage and lymphadenectomy). We used the Charlson Comorbidity Index (13) and Common Terminology Criteria for Adverse Events (CTCAE) Version 5.0 (14), in order to assess comorbidities and post-operative complications respectively. The CTCAE includes different classes of complications, but we decided to consider only those most frequently occurring after thoracic surgery: infections, respiratory and thoracic disorders (prolonged air loss, atelectasis, respiratory failure, chylotorax, hemothorax), blood disorders (anaemia), cardiovascular disorders (atrial fibrillation, atrial flutter, arrhythmia, heart failure), and others (renal failure, ictus, and pulmonary hernia). The severity of each complication is graded according to the intervention it required, as shown in Table 1. We considered adverse events of all grade of severity, but we also performed a separate analysis for grade $\geq 3$ complications. We also considered 30 and 90 -days mortality and the overall survival in patients with at least 5 years of follow-up.

We divided the patients in two groups: Group $\mathrm{T}$ includes patients operated by a trainee while Group $\mathrm{S}$ includes patients operated by a senior surgeon. Then we analyzed only resections performed by VATS.

Continuous variables are expressed as mean values and standard deviation, categorical variables are expressed with absolute and percentage frequencies. Two-sided Chisquare tests or $t$-tests for unpaired data were performed as appropriate. A P value $<0.05$ was considered statistically significant.

This was a retrospective study, so the ethical review was excused and individual consent was waived. The study was conducted in accordance with the Declaration of Helsinki (as revised in 2013).

\section{Results}

A total of 857 procedures were performed over the study 
Table 1 Grades of the Common Terminology Criteria for Adverse Events (CTCAE) Version 5.0: the grades refer to the severity of the adverse event

\begin{tabular}{ll}
\hline Grade & Common terminology criteria \\
\hline Grade 1 & Mild; asymptomatic or mild symptoms; clinical or diagnostic observations only; intervention not indicated \\
Grade 2 & Moderate; minimal, local or non-invasive intervention indicated; limiting age appropriate instrumental activities of daily living \\
Grade 3 & $\begin{array}{l}\text { Severe or medically significant but not immediately life-threatening; hospitalization or prolongation of hospitalization } \\
\text { indicated; disabling; limiting self-care activities of daily living }\end{array}$ \\
Grade 4 & Life-threatening consequences; urgent intervention indicated \\
Grade 5 & Death related to adverse event \\
\hline
\end{tabular}

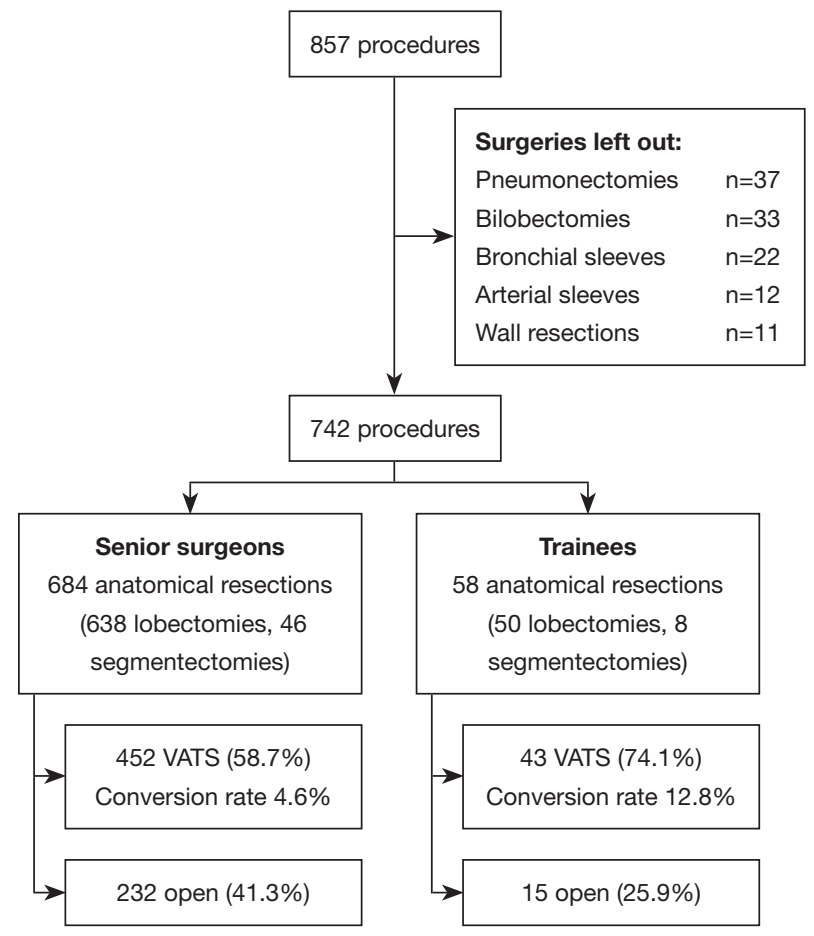

Figure 1 Flow chart of selected patients. VATS, video-assisted thoracoscopic technique.

period. Excluding bilobectomies, pneumonectomies and anatomical resections with arterial or bronchial sleeve or wall resections, we selected 742 interventions: 688 lobectomies $(92.7 \%)$ and 54 anatomic segmentectomies $(7.3 \%)$. Fifteen residents carried out 58 operations: 50 lobectomies and 8 segmentectomies. Out of these, 43 (74.1\%) were performed adopting VATS approach, with a conversion rate of $4.6 \%$. Senior surgeons performed 684 operations: 638 lobectomies and 46 segmentectomies. VATS technique was adopted in $452(58.7 \%)$ of these resections, and the conversion rate was $12.8 \%$ (Figure 1).
Demographical and pre-operative data are shown in Table 2. There were no differences in the demographic and clinical or pathological factors between the two groups.

We reported type of pulmonary resection, final histological diagnosis, p-stage and intra-operative lymphadenectomy details (Table 3).

The majority of the interventions were performed for non-small cell lung cancer (NSCLC) in both groups (Group T 86.0\%, Group S 90.4\%). A systematic lymphadenectomy was carried out in $59.5 \%$ of Group T patients and in $63.8 \%$ of Group S patients. At least 4 lymph node stations were sampled in $86.5 \%$ of patients in Group $\mathrm{T}$ and in $89.8 \%$ in Group S.

The mean operative time was about 20 minutes shorter in Group S compared to Group T. The length of stay was higher in Group S. There were no statistically significant differences between the two groups in terms of operative, post-operative complications and mortality (Table 4). Complications occurred in 30\% of patients in Group $\mathrm{T}$ (infections $2.3 \%$, respiratory and thoracic disorders $18.6 \%$, blood disorders $4.7 \%$ ) and $38.2 \%$ in Group S (infections $7.7 \%$, respiratory and thoracic disorders $19.1 \%$, blood disorders $2.9 \%$ and others $1.5 \%$ ). Postoperative mortality at 30 (Group T 0.0\%, Group S 0.4\%) and 90 days (Group T $2.3 \%$, Group S $0.7 \%$ ) was low and comparable between the two groups. Overall survival at 5 years was $74.3 \%$ in Group $\mathrm{T}$ and $72.2 \%$ in Group S.

\section{Discussion}

VATS major pulmonary resections have become the most common procedures in thoracic surgery centres, as its feasibility has long been well established, and it has been proven to be associated with better outcomes (i.e., hospital stay, complications, postoperative pain) compared to open 
Table 2 Demographical and pre-operative data

\begin{tabular}{lccc}
\hline Variables & Group T $(\mathrm{n}=58)$ & Group S (n=463) & P \\
\hline Age, years, mean (SD) & $68(9.6)$ & $65.9(11.1)$ & 0.097 \\
Sex, male, $\mathrm{n}(\%)$ & $33(56.9)$ & $273(59.0)$ & 0.873 \\
Charlson Comorbidity Index, mean (SD) & $5.2(2.0)$ & $4.8(1.9)$ & 0.111 \\
Induction therapy, n (\%) & $0(0.0)$ & $26(5.6)$ & 0.126 \\
Previous lung resection, n (\%) & $0(0.0)$ & $8(1.7)$ & 0.658 \\
FEV1\%, mean (SD) & $92.8(33.0)$ & $93.9(22.2)$ & 0.822 \\
DLCO\%, mean (SD) & $78.3(18.2)$ & $76.2(15.5)$ & 0.549 \\
\hline
\end{tabular}

Table 3 Final histological diagnosis, p-stage and intra-operative lymphadenectomy

\begin{tabular}{|c|c|c|c|}
\hline Variables & Group T $(n=58)$ & Group S ( $n=463)$ & $P$ \\
\hline RUL & $12(27.9)$ & $108(39.8)$ & 0.190 \\
\hline ML & $4(9.3)$ & $18(6.6)$ & 0.749 \\
\hline RLL & $8(18.6)$ & $48(17.7)$ & 0.999 \\
\hline LLL & $7(16.3)$ & $35(12.8)$ & 0.711 \\
\hline Segmentectomy & $5(11.6)$ & $21(7.7)$ & 0.571 \\
\hline Histology, n (\%) & 43 & 272 & \\
\hline Primary lung cancer & $37(86.0)$ & $246(90.4)$ & 0.539 \\
\hline Lymph nodes removed in NSCLC ( $\geq 14), \mathrm{n}(\%)$ & $22(59.5)$ & $157(63.8)$ & 0.741 \\
\hline Equal or more than 4 lymph node stations, $n(\%)$ & $32(86.5)$ & $221(89.8)$ & 0.741 \\
\hline Stage NSCLC (total), n (\%) & 37 & 246 & \\
\hline I & $28(75.7)$ & $171(69.5)$ & 0.567 \\
\hline II & 5 (13.5) & $51(20.7)$ & 0.420 \\
\hline III & $4(10.8)$ & $23(9.3)$ & 0.999 \\
\hline IV & $0(0.0)$ & $1(0.4)$ & 0.999 \\
\hline
\end{tabular}

VATS, video-assisted thoracoscopic technique; RUL, right upper lobectomy; ML, middle lobectomy; RLL, right lower lobectomy; LUL, left upper lobectomy; LLL, left lower lobectomy; NSCLC, non-small cell lung cancer.

surgery (15-17). Given these advantages, VATS approach has been increasingly adopted in thoracic surgery, while open surgery is more and more often used only to manage complex cases. As thoracoscopic surgery has become the mainstream technique for thoracic surgery, trainees have been expected to improve their skills in this field.
The results of our study, comparing VATS major pulmonary resections carried out by experienced surgeons and residents, show that VATS anatomical resection can be safely performed by trainees. In fact, post-operative outcomes and oncological results were similar between the two groups. The population characteristics were comparable 
Table 4 Operative, post-operative data, morbidity and mortality

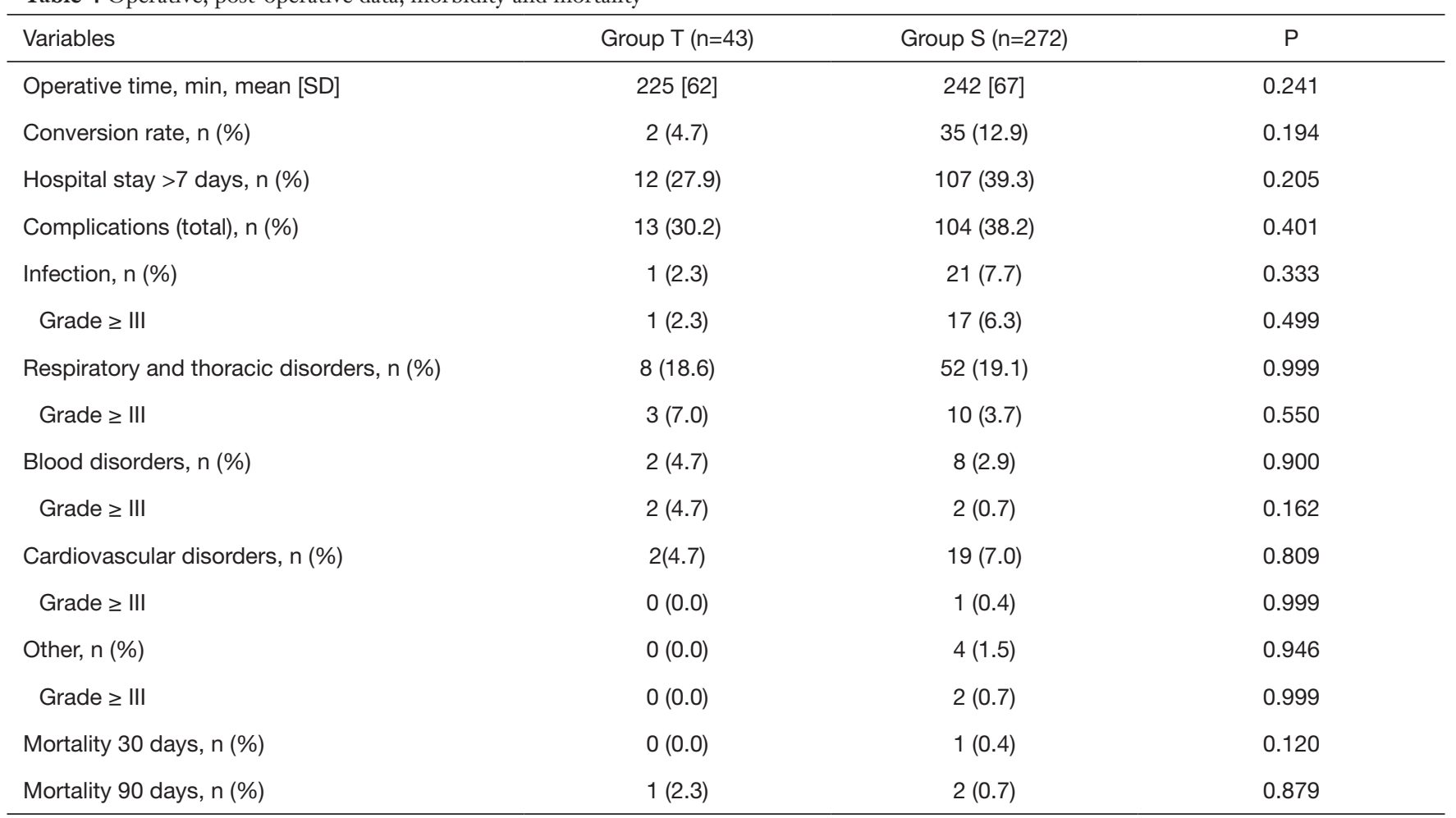

between the two groups, but some aspects are to be pointed out: first of all, patients having a history of previous pulmonary resections or undergoing surgery after induction therapy were operated by a senior surgeon. This does not surprise us: difficult case is faced by senior surgeon. Indeed, induction therapy leads to a greater frailty of the patient and a higher risk of post-operative complications (18). Instead, trainees were more likely to perform easier lobectomies in patients with a pathological stage I disease.

The two groups were comparable in terms of lymphadenectomy. Lobectomy with systematic lymph node dissection is the standard surgical practice for the treatment of lung cancer because it is an important investigative procedure in the disease staging process. Appropriate lymph nodes assessment is a hallmark of surgical quality of curative intent operations for lung cancer. Systematic lymphadenectomy provides the most truthful pathological TNM, which is decisive in directing adjuvant therapy $(19,20)$.

When analysing the outcomes, operative time was found to be slightly lower in Group S, compared to Group T. Conversion rate, hospital stay (longer than 7 days) and complications were higher in Group $\mathrm{S}$ than in Group T (12.9\% vs. $4.7 \%$, 39.3\% vs. $27.9 \%$, $38.2 \%$ vs. $30.2 \%$ respectively); this finding could be related to many factors, such as greater complexity of cases faced by senior surgeons (i.e., previous surgery, induction therapy, disease stage).

The results of our study lead us to believe that a trainee does not necessarily have to learn open first and then VATS technique. The idea that a trainee must have an extensive experience in open surgery before performing VATS anatomical resections is still a paradigm to this day, yet we are persuaded that open surgery is not preliminary to VATS surgery. We rather think that open surgery should be considered complementary to VATS surgery; however, the open approach remains a really important professional skill for any thoracic surgeon. A period in lung transplant unit and general surgery should be included in the Thoracic Surgery Training Program, in order to ensure that residents achieve an adequate level of training in open surgery. Another aspect to consider is the patient's safety. Some authors suggest to adopt risk-free based teaching strategies in dedicated platforms such as simulation tools (blackboxes, wet labs, 3D virtual reality simulators) and dedicated models (animals or cadaver) accompanied by direct teaching in the operating room ("visual acquisition process") (21). Thus, most surgeons do not get an opportunity for hands- 
on training of thoracoscopic surgery. Virtual simulators could represent an alternative to wet labs but, to this day, they have proved useful mostly in the learning of the basic movements a trainee must assimilate. Therefore, progress regarding the simulation of more complex procedures as VATS major pulmonary resections is yet to be made. Although these strategies could be a resource to develop the skills of surgical residents, we think that performing VATS procedures in the operating room alongside an experienced surgeon still remains a fundamental part of the training in order for residents to achieve autonomy.

\section{Conclusions}

Our study shows that trainees can safely perform VATS major pulmonary resections without compromising patients 'outcome. Notably, in our series, trainee practice did not affect surgical time, conversion rate, post-operative outcomes, oncological radicality and mortality. The debate on whether trainees could perform VATS major pulmonary resections without learning the open approach first, is still open. Therefore, the best way to teach young surgeons is yet to be established. However, when learning VATS as well as open technique, the fundamental aspect remains the experience acquired in the operating room with an already skilled surgeon. This way the trainee can safely carry on the procedure knowing that, as in driving school, his teacher will be able to help and guide him, and to use dual control driving to prevent him from making mistakes.

\section{Acknowledgments}

Funding: None.

\section{Footnote}

Provenance and Peer Review: This article was commissioned by the Guest Editors (Francesco Zaraca, Reinhold Perkmann, Luca Bertolaccini and Roberto Crisci) for the series "Thoracic Surgery Without Borders" published in Current Challenges in Thoracic Surgery. The article has undergone external peer review.

Conflicts of Interest: All authors have completed the ICMJE uniform disclosure form (available at https://ccts. amegroups.com/article/view/10.21037/ccts.2020.02.06/ coif). The series "Thoracic Surgery Without Borders" was commissioned by the editorial office without any funding or sponsorship. The authors have no other conflicts of interest to declare.

Etbical Statement: The authors are accountable for all aspects of the work in ensuring that questions related to the accuracy or integrity of any part of the work are appropriately investigated and resolved. This was a retrospective study, so the ethical review was excused and individual consent was waived. The study was conducted in accordance with the Declaration of Helsinki (as revised in 2013).

Open Access Statement: This is an Open Access article distributed in accordance with the Creative Commons Attribution-NonCommercial-NoDerivs 4.0 International License (CC BY-NC-ND 4.0), which permits the noncommercial replication and distribution of the article with the strict proviso that no changes or edits are made and the original work is properly cited (including links to both the formal publication through the relevant DOI and the license). See: https://creativecommons.org/licenses/by-nc-nd/4.0/.

\section{References}

1. Rodgers-Fischl PM, Martin JT, Saha SP. Video-Assisted Thoracoscopic versus Open Lobectomy: Costs and Outcomes. South Med J 2017;110:229-33.

2. Howington JA, Blum MG, Chang AC, et al. Treatment of stage I and II non-small cell lung cancer: Diagnosis and management of lung cancer, 3rd ed: American College of Chest Physicians evidence-based clinical practice guidelines. Chest 2013;143:e278S-e313S.

3. Whitson BA, Andrade RS, Boettcher A, et al. Videoassisted thoracoscopic surgery is more favourable than thoracotomy for resection of clinical stage I non-small cell lung cancer. Ann Thorac Surg 2007;83:1965-70.

4. McKenna RJ Jr. Complications and learning curves for video-assisted thoracic surgery lobectomy. Thorac Surg Clin 2008;18:275-80.

5. Zhao H, Bu L, Yang F, et al. Video-assisted thoracoscopic surgery lobectomy for lung cancer: the learning curve. World J Surg 2010;34:2368-72.

6. Petersen RH, Hansen HJ. Learning curve associated with VATS lobectomy. Ann Cardiothorac Surg 2012;1:47-50.

7. Gonfiotti A, Bongiolatti S, Borgianni S, et al.

Development of a video-assisted thoracoscopic lobectomy program in a single institution: results before and after completion of the learning curve. J Cardiothorac Surg 2016;11:130. 
8. Hansen HJ, Petersen RH. Video-assisted thoracoscopic lobectomy using a standardized three-port anterior approach - The Copenhagen experience. Ann Cardiothorac Surg 2012;1:70-6.

9. Gonzalez-Rivas D, Paradela M, Fernandez R, et al. Uniportal video-assisted thoracoscopic lobectomy: two years of experience. Ann Thorac Surg 2013;95:426-32.

10. Nosotti M, Baisi A, Mendogni P, et al. Muscle sparing versus posterolateral thoracotomy for pulmonary lobectomy: randomised controlled trial. Interact Cardiovasc Thorac Surg 2010;11:415-9.

11. Lardinois D, De Leyn P, Van Schil P, et al. ESTS guidelines for intraoperative lymph node staging in non-small cell lung cancer. Eur J Cardiothorac Surg 2006;30:787-92.

12. Samayoa AX, Pezzi TA, Pezzi CM, et al. Rationale for a Minimum Number of Lymph Nodes Removed with Non-Small Cell Lung Cancer Resection: Correlating the Number of Nodes Removed with Survival in 98,970 Patients. Ann Surg Oncol 2016;23:1005-11.

13. Charlson ME, Pompei P, Ales KL, et al. A new method of classifying prognostic comorbidity in longitudinal studies: development and validation. J Chronic Dis 1987;40:373-83.

14. Common Terminology Criteria for Adverse Events (CTCAE) Version 5.0 (published: November 27, 2017). Available online: https://ctep.cancer.gov/

doi: $10.21037 /$ ccts.2020.02.06

Cite this article as: Mazzucco A, Palleschi A, Musso V, Bonitta G, Nosotti M. New frontiers in VATS lobectomy learning: the experience of the thoracic surgery residency program in Milan. Curr Chall Thorac Surg 2020;2:25.
protocolDevelopment/electronic_applications/ctc.htm

15. Onaitis MW, Petersen RP, Balderson SS, et al.

Thoracoscopic lobectomy is a safe and versatile procedure: experience with 500 consecutive patients. Ann Surg 2006;244:420-5.

16. Watanabe A, Koyanagi T, Ohsawa H, et al. Systematic node dissection by VATS is not inferior to that through an open thoracotomy: a comparative clinicopathologic retrospective study. Surgery 2005;138:510-7.

17. Whitson BA, Groth SS, Duval SJ, et al. Surgery for earlystage non-small cell lung cancer: a systematic review of the video-assisted thoracoscopic surgery versus thoracotomy approaches to lobectomy. Ann Thorac Surg 2008;86:200816; discussion 2016-8.

18. Venuta F, Anile M, Diso D, et al. Operative complications and early mortality after induction therapy for lung cancer. Eur J Cardiothorac Surg 2007;31:714-7.

19. Thomas PA. Lymph node dissection during sublobar resection: why, when and how? J Thorac Dis 2018;10:S1145-50.

20. Krantz SB, Lutfi W, Kuchta K, et al. Improved Lymph Node Staging in Early-Stage Lung Cancer in the National Cancer Database. Ann Thorac Surg 2017;104:1805-14.

21. Divisi D, Barone M, Zaccagna G, et al. Video-assisted thoracoscopic surgery lobectomy learning curve: what program should be offered in a residency course? J Vis Surg 2017;3:143. 